\title{
A rare case report of heavy dose colchicine induced acute kidney injury
}

\author{
Hongzhen Zhong ${ }^{1 \dagger}$, Zhiqing Zhong ${ }^{1 \dagger}$, Hongyan $\mathrm{Li}^{2 \dagger}$, Tianbiao Zhou ${ }^{{ }^{*}}$ and Weiji Xie
}

\begin{abstract}
Background: Colchicine is a natural alkaloid that is mainly used for the treatment of inflammatory diseases. Effective and toxic doses are very similar, but case reports of higher colchicine doses inducing acute toxicosis is rare.

Case presentation: A 19-year-old woman was sent to the emergency room for taking 80 colchicine tablets ( $0.5 \mathrm{mg}$ per tablet) $44 \mathrm{~h}$ previously. The main physical symptom was abdominal pain. Following ingestion, the patient suffered multi-system failure including renal, respiratory, circulatory, and digestive. Continuous renal replacement therapy (CRRT) and other treatment measures were used to remove metabolic wastes and poisons, and to treat other complications. Renal function was restored after a series of treatments.

Conclusion: We report a case of an acute kidney injury induced by an overdose of colchicine. CRRT and a series of related treatments were beneficial for the treatment of colchicine poisoning.
\end{abstract}

Keywords: Colchicine, Acute colchicine intoxication, Acute kidney injury, Continuous renal replacement therapy (CRRT), Treatment

\section{Background}

Colchicine is a natural alkaloid that is mainly used for the treatment of inflammatory diseases, such as gout and familial Mediterranean fever. Poisoning, a major public health concern around the world, is a frequent cause of referral to medical emergencies, and requires a rapid and precise diagnosis for adequate treatment [1, 2]. Effective and toxic doses are very similar, but case reports of higher colchicine doses inducing acute toxicosis is rare [3]. Colchicine intoxication is often accompanied by severe adverse complications and mortality, and there is no antidote, so it represents a clinical toxicology emergency [4]. We report a case of an acute kidney injury induced by a high dose of colchicine to as a clinical example for the treatment of acute colchicine intoxication.

\footnotetext{
* Correspondence: zhoutb@aliyun.com

${ }^{\dagger}$ Hongzhen Zhong, Zhiqing Zhong and Hongyan Li contributed equally to this work.

'Department of Nephrology, the Second Affiliated Hospital of Shantou

University Medical College, Shantou 515041, China

Full list of author information is available at the end of the article
}

\section{Case presentation}

On 2018.01.24, a 19-year-old woman was admitted to the emergency room after taking 80 colchicine tablets (0.5 mg per tablet) $44 \mathrm{~h}$ previously. She had an argument with her boyfriend and ingested the colchicine to commit suicide. She was previously healthy and had no history of drug allergies. The clinical symptoms were abdominal pain, watery diarrhea and profuse vomiting. Other symptoms were muscle weakness and palpitations.

On physical examination, the temperature was $38.7^{\circ} \mathrm{C}$, pulse rate was 145 , and respiration rate was 39. Her blood pressure was $122 / 60 \mathrm{mmHg}$, and she weighed $43 \mathrm{~kg}$. Physical examination indicated upper abdominal pain.

Laboratory test results before treatment indicated the following: a white blood cell (WBC) count of $28.2 \times 109 / \mathrm{L}$, and other values such as red blood cell (RBC) count, hemoglobin (HGB) level and platelet (PLT) count were within the normal ranges. The levels of $\alpha$-L-fructosidase (AFU), adenosine deaminase (ADA), alanine aminotransferase (ALT), aspartate aminotransferase (AST), alkaline phosphatase (ALP) and lactate dehydrogenase (LDH) were increased to 98, 57, 84, 408, 378 and 3494 respectively from 

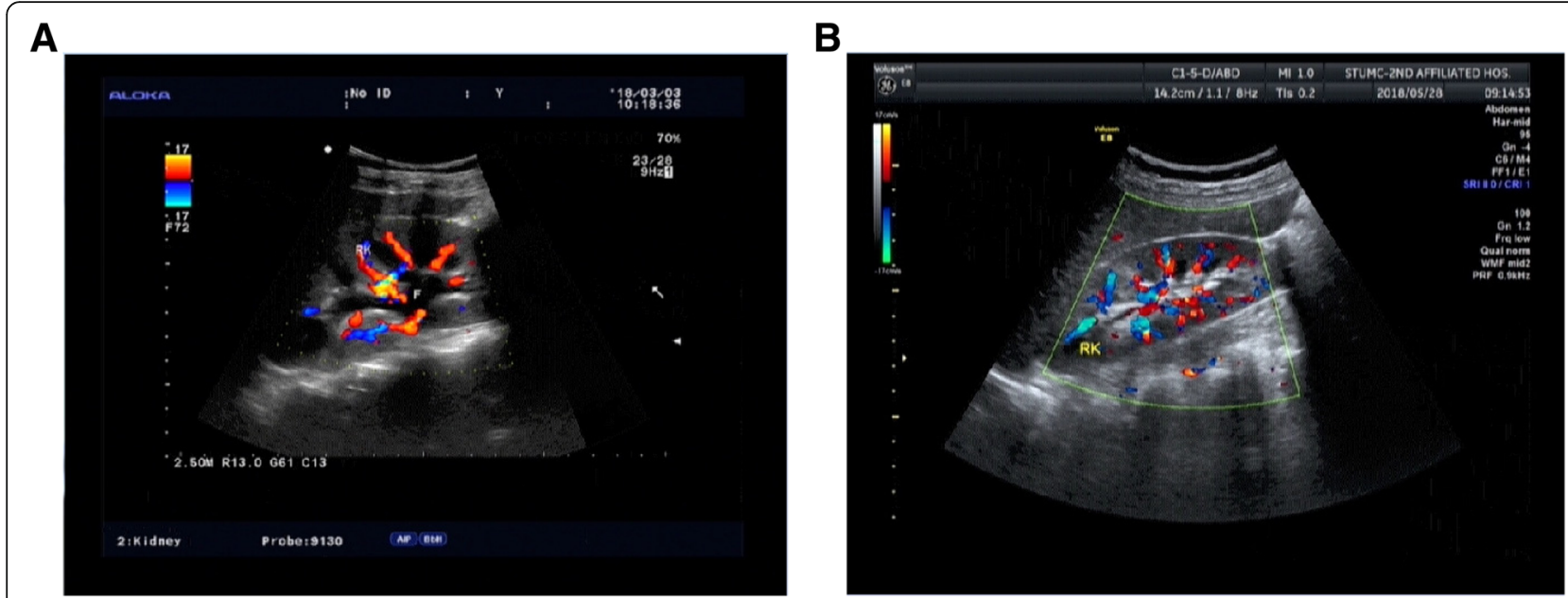

Fig. 1 Renal ultrasound indicated: a: Pre-treatment situation: The kidneys have clear outlines, normal shapes, smooth capsules, increased cortical echo, reduced medulla echo, and clear boundaries of the cortex and medulla. b: After treatment: The kidneys have clear contours, normal size and shape, smooth capsules, clear boundaries between the medulla and cortex, and even echoes

reference values (reference range were $12-40 \mathrm{U} / \mathrm{L}, 0-$ $50 \mathrm{U} / \mathrm{L}, 5-40 \mathrm{U} / \mathrm{L}, 8-40 \mathrm{U} / \mathrm{L}, 40-150 \mathrm{U} / \mathrm{L}, 109.0-$ $245.0 \mathrm{U} / \mathrm{L}$, respectively). Biochemical abnormalities also included hypokalemia and hypoglycemia. Plasma prothrombin time (PT) and activate part plasma prothrombin time (APTT) were significantly prolonged at $23.50 \mathrm{~s}$ and $52.40 \mathrm{~s}$ respectively. The level of $\mathrm{N}$-terminal pronatriuretic peptide (NT-proBNP) was $5950 \mathrm{pg} / \mathrm{mL}$, which is abnormal with values higher than $450 \mathrm{pg} / \mathrm{mL}$ in the populations under 50 -year-old (referrence value). The Electrocardiograms revealed sinus tachycardia.

Hemoperfusion was performed to remove circulating toxins. The patients refused other treatments in Department of Emergency. After $44 \mathrm{~h}$ later, gastrointestinal hemorrhage, acute liver injury, acute kidney injury and acute cardiac damage were reported, along with prolonged coagulation. She was then admitted to the intensive care unit. Adequate fluid and electrolyte replacement, oxygenation and other supportive cares was initiated. Anti-inflammatory ceftriaxone sodium was used. Since the unobstructed drainage tube revealed brown fluid, gastric lavage and charcoal were not recommended.

During two days after admission, she presented with high fever, subcutaneous hemorrhage and anuria. Arterial blood gas analysis suggested hyperlactinemia. Uric convention and occult stool were positive for blood. The level of Creatine Kinase-MB had sharply increased to $182 \mathrm{U} / \mathrm{L}$ and HGB level and PLT count rapidly plunged to $49 \mathrm{~g} / \mathrm{L}$ and $11 \times 10^{9} / \mathrm{L}$, respectively. APTT had increased to $72.4 \mathrm{~s}$. At that time, renal function deteriorated and anuria was observed, and the levels of serum creatinine $(\mathrm{Cr})$ and blood urea urea (BUN) were elevated. CRRT was used to remove metabolic wastes and poisons and promoted recovery of renal function. RBC, PLT and plasma were transfused to alleviate anemia and deficient coagulation.

Due to the high dosage of colchicine ingestion, the patient progressed to exhibit shortness of breath, high fever, and subsequent coma. The vital signs at this point were: a heart rate of 87 , respiration rate of 21 , and the blood pressure was $103 / 52 \mathrm{mmHg}$. Blood lactic acid levels were slightly increased. Hyperleukocytosis, low hemoglobin and thrombocytopenia were present. Emergency treatment with tracheal intubation via oral cavity was initiated.

On 2018-02-01, the level of BUN and CK were elevated and anuria was noted. Maintenance therapy with CRRT was initiated to clear metabolic toxins. The arterial blood gas results were generally normal, and she was extubated and provide with supplemental oxygen through a nasal tube. The WBC count returned normal levels, and blood coagulation and liver function were gradually normalized as well.

Following a month of treatment, urine volume increased, but renal function indicators remained abnormal. In addition, HGB levels gradually increased but remained low. Intermittent CRRT and diuretics were administered.

On 2018-03-06, her urine volume reached $3000 \mathrm{ml}$. Renal ultrasound showed the kidneys were full and diffusely changed (Fig. 1a). Urinary albumin-to-creatinine ratio (reference range of $0-200 \mathrm{mg} / \mathrm{g}$ ) was also abnormal as displayed in Fig. 4. Intermittent hemodialysis was performed and renal function improved. Three days later, 


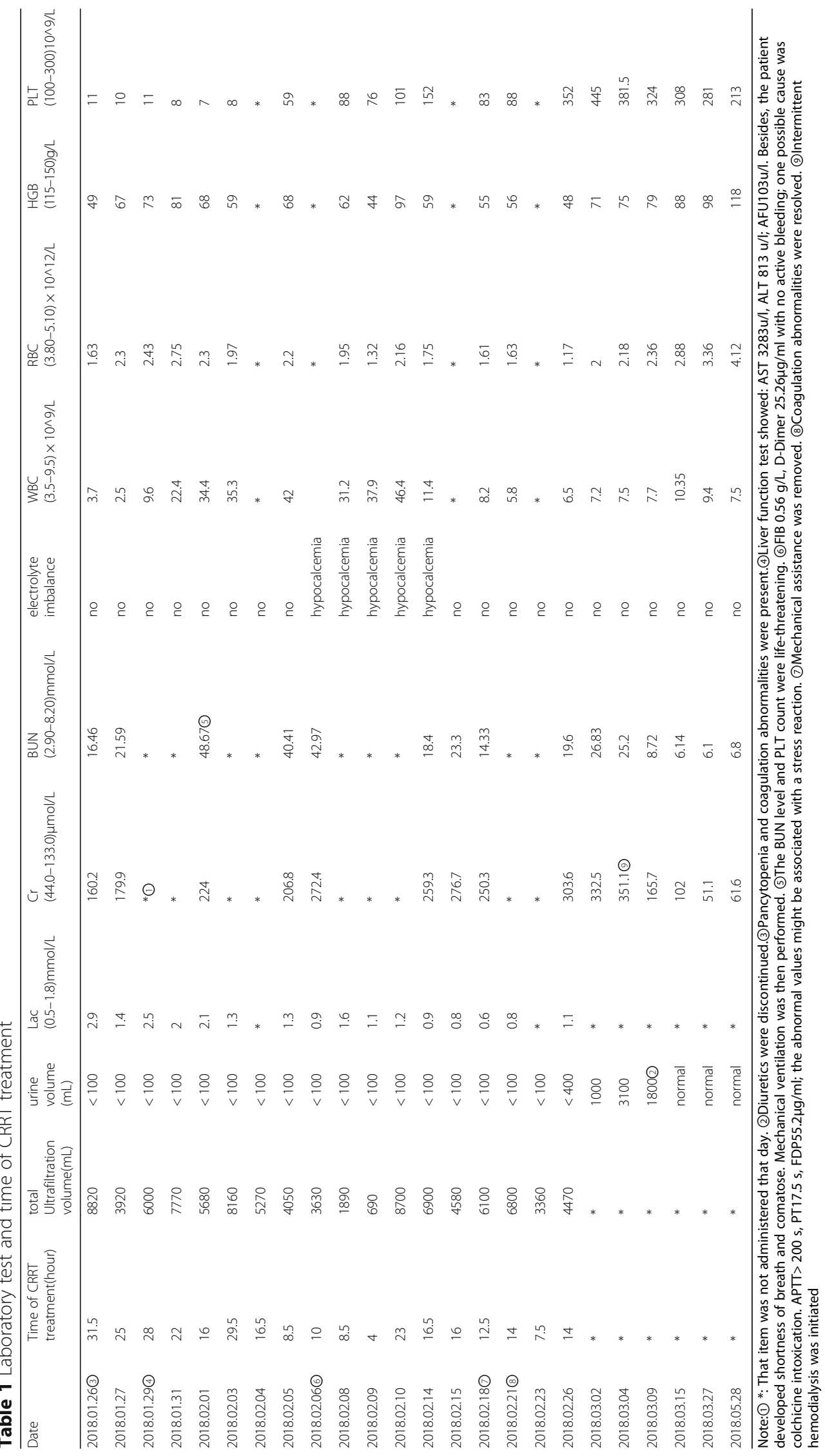




\section{Changes of creatinine level}

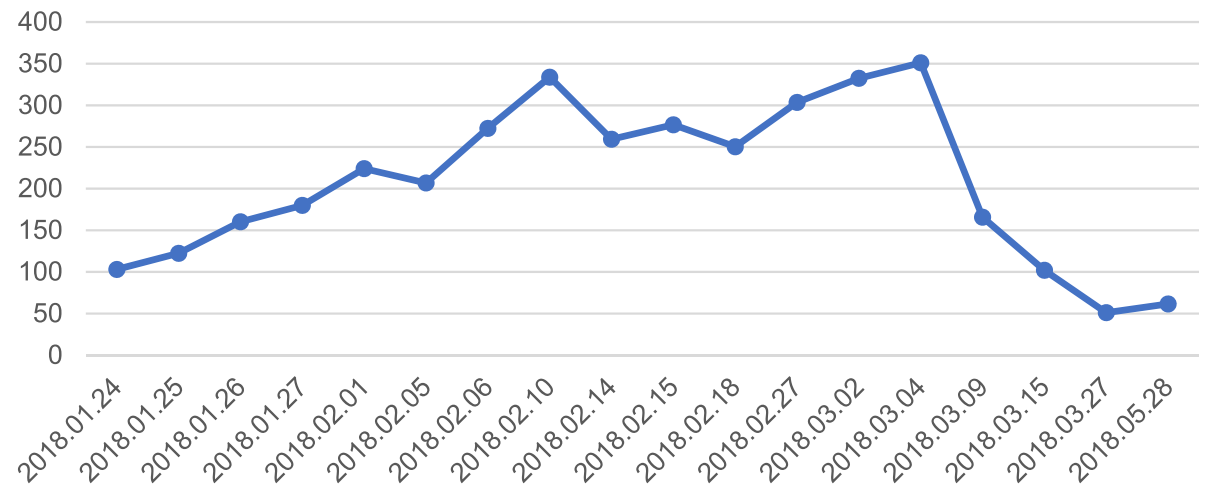

Fig. 23 days after colchicine ingestion, the level of creatinine increased gradually. CRRT was performed since admission, and creatinine level mildly increased. After an intermittent hemodialysis, the level of creatinine dropped off significantly, and then it returned back to normal level

the levels of $\mathrm{Cr}$ and BUN were also normal, and the patient was discharged. (Blood and urine specimens, and blood biochemistry were reviewed one week later. These values and the time of CRRT treatment are shown in Table 1. Changes of $\mathrm{Cr}$ level and BUN level are presented in Figs. 2 and 3. On 2018.05.28, the renal ultrasound urinary albumin-to-creatinine ratio were normal (Fig. $1 \mathrm{~b}$ and 4). The treatment timeline is shown in Additional file 1: Figure S1.

\section{Discussion and conclusions}

Colchicine has a low therapeutic index and ingestion of a dose of $0.8 \mathrm{mg} / \mathrm{kg}$ can result in death $[5,6]$. The total quantity of colchicine taken in this case was $40 \mathrm{mg}$, and his body weight was $43 \mathrm{~kg}$. Colchicine poisoning is an uncommon but life-threatening, and there is no effective antidote at present. Supportive therapy is the primary option [7-9]: (1) gastric lavage within $60 \mathrm{~min}$ of ingestion, following by activated charcoal help prevent enterohepatic recirculation of the drug. (2) Early fluid resuscitation and multi-organ adjuvant therapy should be performed as soon as possible. (3) Colchicine is a neutral fat-soluble alkaloid, and it reaches the peak serum concentration after 0.5-3.0 h. Hemodialysis and hemoperfusion are ineffective, and plasma exchange and CRRT can be applied if necessary. (4) Symptomatic supportive treatment for complications, such as pulmonary infection, hematopoietic suppression, should be initiated.

Colchicine is a lipophilic compound and is rapidly absorbed from the gastrointestinal tract after oral administration. It's plasma peak concentrations are detected at 0.5 to $3 \mathrm{~h}$ after ingestion [10]. After assessment of 17 pediatric cases with colchicine poisoning, Alaygut et al. [11] concluded that patients arrived at the hospital on average $7.3 \mathrm{~h}$ after taking colchicine. We reviewed the medical history of this case and found that the

\section{Changes of BUN level}

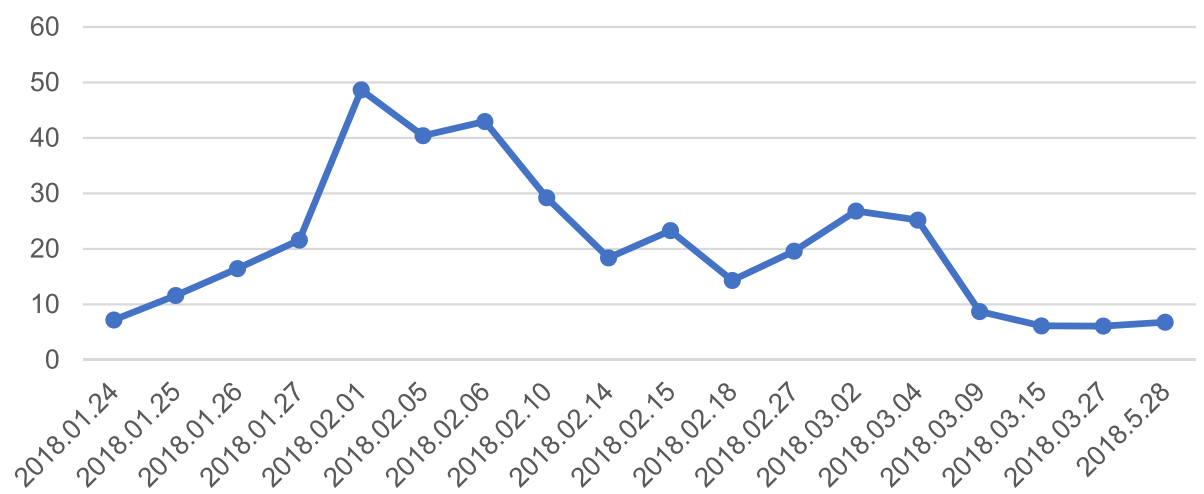

Fig. 3 The level of BUN increased to the pole 10 days after colchicine ingested. CRRT was performed to remove metabolite. As other indicators were generally normal, intermittent hemodialysis was administered. BUN gradually returned to normal 


\section{Changes of Urine Proteinuria/Creatinine Ratio level}

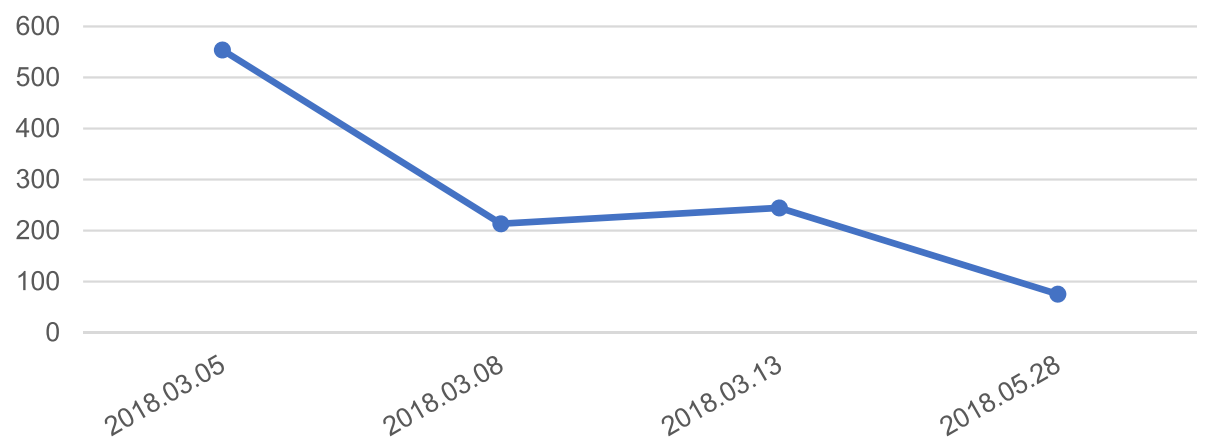

Fig. 4 Following treatment, the urinary proteinuria/creatinine ratio decreased significantly, and then returned to normal

patient was sent to hospital $6 \mathrm{~h}$ after ingesting colchicine. However, the patient refused all treatment in emergency department. Forty-four hours after being admitted, gastrointestinal hemorrhage, acute liver injury, acute kidney injury and acute cardiac damage were reported, along with deficient coagulation. Based on these observations, gastric lavage and activated charcoal were not administered.

Various factors such as depletion of volume/hypotension, rhabdomyolysis and multi-organ failure contribute to renal failure after colchicine intoxication [12]. Up to $20 \%$ of colchicine is excreted by the kidneys $[13,14]$, and this is often associated with renal impairment [15]. In the current case, depletion of volume/hypotension and rhabdomyolysis was likely to be the primary cause of acute renal insufficiency and continuous anuria. In addition, cells with a high division index, such as gastrointestinal epithelial cells, renal tubular epithelial cells (RTEC), and bone marrow hematopoietic cells are highly susceptible to the toxic effect of colchicine [16]. Therefore, RTEC toxicity to colchicine was also a critical cause of acute kidney injury and continuous anuria. Fab fragments is reported to be of value in the treatment of colchicine poisoning in animal studies [6, 1719] and clinical application [20], but it is not currently available and there are few clinical reports. There, supportive therapy was chosen for the patient. Fluid and electrolyte supplementation and CRRT were performed to improve renal perfusion/hemodynamics and address impaired kidney function respectively. As the volume of urine increased, the intermittent hemodialysis was performed to eliminate uremic toxins instead of CRRT. Renal function gradually recovered with this treatment regimen.

There are some limitations to this case study. Mostly notably a lack of colchicine concentration monitoring during the clinical treatment. The absence of renal biopsy is also unfortunate, but the diagnosis was clear based on the presented values. Lastly, the exact mechanism of colchicine poisoning remains unknown, and there is no effective antidote.

In conclusion, we present a case of acute kidney injury and severe complications induced by high dose colchicine following delayed treatment. We report that applied CRRT in the oliguria stage was beneficial for treatment, particularly with alleviating the progression of renal damage. Renal function and morphology returned to normal four months after the initial presentation.

\section{Additional file}

Additional file 1: Figure S1. Treatment timeline of this patient. (DOCX $134 \mathrm{~kb})$

\section{Abbreviations}

ADA: Adenosine deaminas; AFU: a-fucosidas; ALP: Alkaline phosphatase; ALT: Alanine aminotransferase; APTT: Activate part plasma prothrombin time; AST: Aspartate aminotransferase; BUN: Blood urea urea; Cr: Serum creatinine; CRRT: Continuous renal replacement therapy; HGB: Hemoglobin;

LDH: Lactate dehydrogenase; NT-proBNP: N-terminal pronatriuretic peptide; PLT: Platelet; PT: Plasma prothrombin time; RBC: Red blood cell; RTEC: Renal tubular epithelial cells; WBC: White blood cell

\section{Acknowledgements}

The authors thank the staff of the ICU Department and Emergency Department of the Second Affiliated Hospital of Shantou University Medical College for their facilities and collaboration.

\section{Funding}

This study was supported by the Guangzhou Medical Key Discipline Construction Project (2017-2019).

\section{Availability of data and materials}

The datasets used and/or analyzed during the current study available from the corresponding author on reasonable request.

\section{Authors' contributions}

HZZ, ZQZ, HYL, TBZ and WJX analyzed and interpreted patient data. HZZ and TBZ were the primary contributors in writing the manuscript. HZZ, ZQZ and WJX made the figures based on patient data. All authors read and approved the final manuscript. 


\section{Ethics approval and consent to participate}

This study has been performed in accordance with the ethical standards laid down in "Declaration of Helsinki 1964" and its later amendments or comparable ethical standards. One patient was enrolled in the study and informed consent forms were signed by this patient.

\section{Consent for publication}

Written consent was obtained from the patient to report individual data within the text and images for publication.

\section{Competing interests}

The authors declare that they have no competing interests.

\section{Publisher's Note}

Springer Nature remains neutral with regard to jurisdictional claims in published maps and institutional affiliations.

\section{Author details}

'Department of Nephrology, the Second Affiliated Hospital of Shantou University Medical College, Shantou 515041, China. ${ }^{2}$ Department of Nephrology, Huadu District People's Hospital of Guangzhou, Southern Medical University, Guangzhou, China.

Received: 14 June 2018 Accepted: 23 October 2018 Published online: 30 October 2018

\section{References}

1. Alinejad S, Zamani N, Abdollahi M, Mehrpour O. A narrative review of acute adult poisoning in Iran. Iranian journal of medical sciences. 2017;42(4):32746.

2. Lee SB, Kim DH, Kim T, Lee SH, Jeong JH, Kim SC, Park YJ, Lim D, Kang C. Anion gap and base deficit are predictors of mortality in acute pesticide poisoning. Human \& experimental toxicology. 2018. https://doi.org/10.1177/ 0960327118788146.

3. Kilic SC, Alaygut D, Unal E, Koc E, Patiroglu T. Acute colchicine intoxication complicated with extramedullary hematopoiesis due to filgrastim in a child. J Pediatr Hematol Oncol. 2014;36(7):e460-2.

4. Roddy E, Mallen CD. Colchicine in overdose. The British journal of general practice : the journal of the Royal College of General Practitioners. 2017; 67(655):61.

5. Aghabiklooei A, Zamani N, Hassanian-Moghaddam H, Nasouhi S, Mashayekhian M. Acute colchicine overdose: report of three cases Reumatismo. 2014;65(6):307-11.

6. Peake PW, Pianta TJ, Succar L, Fernando M, Buckley NA, Endre ZH. Fab fragments of ovine antibody to colchicine enhance its clearance in the rat Clinical toxicology (Philadelphia, Pa). 2015:53(5):427-32

7. Polat E, Tuygun N, Akca H, Karacan CD. Evaluation of the colchicine poisoning cases in a pediatric intensive care unit: five year study. The Journal of emergency medicine. 2017;52(4):499-503.

8. Boisrame-Helms J, Rahmani H, Stiel L, Tournoud C, Sauder P. Extracorporeal life support in the treatment of colchicine poisoning. Clinical toxicology (Philadelphia, Pa). 2015;53(8):827-9.

9. Bajramovic-Omeragic L, Calkic L, Hadzic E, Alickovic I. Accidental poisoning with a plant colchicum autumnale: report of two cases. Lijecnicki vjesnik. 2015:137(9-10):288-91.

10. Finkelstein $Y$, Aks SE, Hutson JR, Juurlink DN, Nguyen P, Dubnov-Raz G, Pollak U, Koren G, Bentur Y. Colchicine poisoning: the dark side of an ancient drug. Clinical toxicology (Philadelphia, Pa). 2010;48(5):407-14.

11. Alaygut D, Kilic SC, Kaya A, Oflaz MB, Bolat F, Cevit O, Icagasioglu FD. Assessment of 17 pediatric cases with colchicine poisoning in a 2-year period. Pediatr Emerg Care. 2016;32(3):168-72.

12. Borras-Blasco J, Enriquez R, Sirvent AE, Amoros F, Navarro-Ruiz A, Reyes A. Acute renal failure associated with an accidental overdose of colchicine. Int J Clin Pharmacol Ther. 2005:43(10):480-4.

13. Ferron GM, Rochdi M, Jusko WJ, Scherrmann JM. Oral absorption characteristics and pharmacokinetics of colchicine in healthy volunteers after single and multiple doses. J Clin Pharmacol. 1996;36(10):874-83.

14. Rochdi M, Sabouraud A Girre C, Venet R, Scherrmann JM. Pharmacokinetics and absolute bioavailability of colchicine after i.v. and oral administration in healthy human volunteers and elderly subjects. Eur J Clin Pharmacol. 1994; 46(4):351-4.
15. Medani S, Wall C. Colchicine toxicity in renal patients - are we paying attention? Clin Nephrol. 2016:86(2):100-5.

16. Premaratna R, Weerasinghe MS, Premawardana NP, de Silva HJ. Gloriosa superba poisoning mimicking an acute infection- a case report. BMC pharmacology \& toxicology. 2015;16:27.

17. Sabouraud AE, Urtizberea M, Cano NJ, Grandgeorge M, Rouzioux JM, Scherrmann JM. Colchicine-specific fab fragments alter colchicine disposition in rabbits. J Pharmacol Exp Ther. 1992;260(3):1214-9.

18. Eddleston M, Fabresse N, Thompson A, Al Abdulla I, Gregson R, King T, Astier A, Baud FJ, Clutton RE, Alvarez JC. Anti-colchicine fab fragments prevent lethal colchicine toxicity in a porcine model: a pharmacokinetic and clinical study. Clinical toxicology (Philadelphia, Pa). 2018;56(8):773-81.

19. Fabresse N, Allard J, Sardaby M, Thompson A, Clutton RE, Eddleston M, Alvarez JC. LC-MS/MS quantification of free and fab-bound colchicine in plasma, urine and organs following colchicine administration and colchicine-specific fab fragments treatment in Gottingen minipigs. J Chromatogr B Analyt Technol Biomed Life Sci. 2017;1060:400-6.

20. Baud FJ, Sabouraud A, Vicaut E, Taboulet P, Lang J, Bismuth C, Rouzioux JM, Scherrmann JM. Brief report: treatment of severe colchicine overdose with colchicine-specific fab fragments. N Engl J Med. 1995;332(10):642-5.

\section{Ready to submit your research? Choose BMC and benefit from:}

- fast, convenient online submission

- thorough peer review by experienced researchers in your field

- rapid publication on acceptance

- support for research data, including large and complex data types

- gold Open Access which fosters wider collaboration and increased citations

- maximum visibility for your research: over $100 \mathrm{M}$ website views per year

At $\mathrm{BMC}$, research is always in progress.

Learn more biomedcentral.com/submissions 